\title{
Challenges arising from use of HVDC
}

\author{
Erling Ildstad \\ Department of Electric Power Engineering \\ Norwegian University of Science and Technology \\ NTNU, Trondheim, Norway
}

Erling.ildstad@elkraft.ntnu.no

\begin{abstract}
Direct Current (DC) power systems have been in use since the early 1880 s. However, for more than 100 years the 3 phase AC transmission system has been the dominant transmission system for electric power. The main reason for this is the ease of changing voltage levels and grid connection using reliable AC transformers and breakers. During the last 60 years new converter technology has made HVDC the most efficient and economical long distance point to point power transmission transportation.

In order to satisfy the growing demand of electric energy consumption, new high capacity multi-terminal HVDC systems need to be developed. This is considered an enabling technology for access to remote renewable energy sources such as off-shore wind farms, hydroelectric power and desert solar plants.
\end{abstract}

This review shows that acceptable solutions have to be found to interrupt HVDC short circuit currents. Higher voltage means that new types of reliable HVDC insulation systems have to be developed, including test procedures and design criteria for insulation systems based upon combinations of gas, liquid and solids.

Keywords; HVDC, development, insulation systems,

\section{INTRODUCTION}

Although the 3 phase AC transmission system have been very successful, it does not necessarily mean that it is more efficient than a DC grid under the same voltage levels. The choice of AC versus DC depends upon many different factors, as for example history and tradition, existing infrastructure, available technology, economy and need of environmentally friendly energy generation and transportation. Today there is a growing interest towards application of DC systems for both high voltage transmission and low voltage distribution systems.

In this paper the history and driving trends of this development, of a future hybrid AC/DC grid, will be reviewed. The new challenges this puts on development of reliable DC insulation systems is the main topic of this Symposium. Some of which will be discussed in this paper.

\section{HISTORY AND DRIVING TRENDS}

In 1887, there were 121 Edison power stations in the United States delivering DC electricity to customers located within about 2 to $3 \mathrm{~km}$ from the power station.
For generation and safety reasons the voltage level was limited to $+/-110 \mathrm{~V}$ [1]. Today such a system would be called "distributed generation". Higher voltages could not easily be used because there was no efficient low-cost technology that would allow reduction of a high transmission voltage to a low utilization voltage.

At the same time the competing entrepreneur and engineer $\mathrm{G}$. Westinghouse started developing a longdistance $\mathrm{AC}$ transmission system, using transformers to step up the voltage to transmission of several $\mathrm{kV}$ and step it down to safe levels at several substations along the line. This together with several inventions by N. Tesla (among them the important polyphase induction generator/motor) was the key to the success of the 3 phase AC system. Today Modern transmission grids regularly use AC voltages up to 765,000 volts.

For almost a century the disadvantages of HVDC related to not only voltage variation, but also switching, control, availability and maintenance, made HVDCtransmission feasible only at special point to point grid connections. Such DC links are typically used to improve stability or to effectively transport large amounts of power over long distances. Therefore less than two percent of the all electric transmission is today done by HVDC [2].

Ironically several driving trends and recent developments have made HVDC transmission more reliable and practical; facilitating increased future use of DC systems both for High Voltage transmission and local distribution:

\section{i) Long distance transmission.}

HVDC transmission is in general preferable when large amount of electric power is to be transmitted over long distances. The main reason for this is that fewer conductors are needed to transmit the same amount of power. In addition, environmental concerns causes growing need of cable based DC transmission instead of overhead lines with tall towers and expensive right of way.

In order to satisfy the increasing demand of electric energy consumption, new high capacity transmission systems based upon HVDC have to be developed. So-called "Multiterminal DC Super Grids" are for example considered enabling technology for access to remote renewable energy sources such as off-shore wind farms, hydroelectric power and desert solar plants. HVDC grid studies show that in the North Sea Region it would be beneficial to tap the rich wind and hydro power 
resource of the region and to interconnect the U.K. and Nordic pool with continental Europe [3, 4].

\section{ii) New technology.}

In the early 1950-1960s HVDC point-to-point transmission systems were developed using converter stations based upon mercury and later thyristor valve technology. These are called current source converters (CSC), as they operate with a stiff DC current. Thus the voltage polarity needs to be change, every time the direction of the power flow is changed. Challenges caused by voltage inversion are, however, reduced by recent use of so called voltage source converters (VSC).

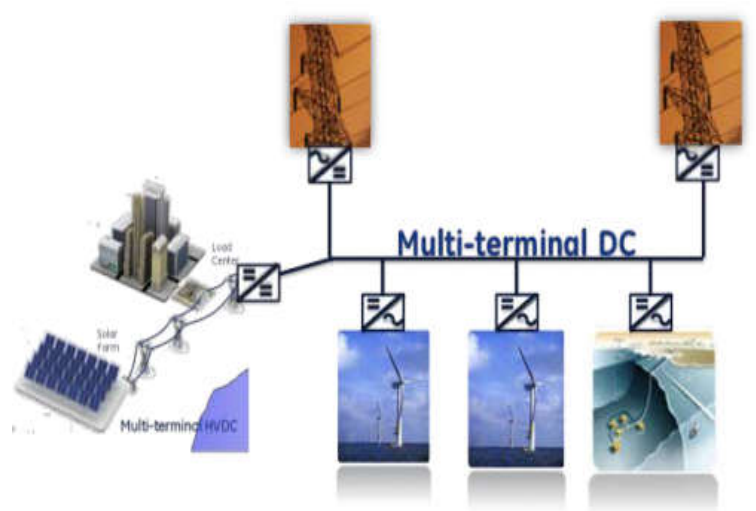

Fig 1

Sketch of a Proposed Multiterminal HVDC grid, providing AC grid connection of remote renewable energy sources and subsea oil and gas production units. (Figure from GE Global Research web illustrations, April 2013)

Here, Isolated Gate Bipolar Transistors (IGBT) are used to electronically generate an $\mathrm{AC}$ voltage with variable amplitude and phase. In addition the power direction is changed by changing the direction of the current flow, keeping the polarity of the dc voltage constant.

Controlling power flow in a multiterminal DC system is more complex than in an $\mathrm{AC}$ system. It requires good communication between all the terminals; power flow must be actively regulated by the converter control system instead of the inherent impedance and phase angle properties of the transmission line. This is promoted by so-called Smart-grid developments; integrating relevant measurement and automation/information technology into power components.

Such a HVDC grid would require step-up HVDC converters and a "dc breaker" is needed to connect the HVDC converter to the grid, since state-of-the-art HVDC converters are uncontrollable during dc short circuit fault. System studies shows that for a $320 \mathrm{kV}$ HVDC grid, this $\mathrm{dc}$ breaker is required to perform open and reclose operation in less than 5 milliseconds with the capability to break current up to 10 kilo-amps [5]. Very recently, in 2012, one commercial dc breaker with such capacity was released [6].

\section{iii) Advantages of distributed DC grids.}

Today there is a widespread use of low voltage electronic power converters. Typically a rectifier is the first component in any household equipment. In addition the need to integrate new distributed generation and energy storage systems have increased the interest in considering a public distribution system using DC voltages. The main idea is to extend the distributed generation systems and uninterruptible power supplies, at levels of LV public DC distribution. The standard voltages for such a DC grid need to be defined and it will take some time to build the new infrastructure. But there are good opportunities to use such grids in new buildings to integrate photovoltaic (PV) energy systems, LED lighting systems and electric vehicles charging systems.

\section{ELECTRICAL INSULATION SYSTEMS FOR HVDC}

There are at least three major factors that make it necessary to design and develop special electrical insulation systems for HVDC apparatus [7]:

a) A DC voltage is not stable. It is switched on, varied or turned off, and in its pure form DC occurs during relatively short periods only.

b) The physical phenomena, governing the electric field distribution, mechanisms of ageing and electrical breakdown differ considerably from those at $\mathrm{AC}$.

c) Different stresses and applications ask for new standards for qualification, maintenance and reliability tests of HVDC systems.

\section{i) Electric field distribution}

In case of AC voltage application the electric field will always be capacitive distributed, while at DC voltage the electric field distribution becomes more complicated. It is governed by a combination of both the permittivity $\varepsilon$ and conductivity $\sigma$ of the insulation system. Initially, immediately after the voltage is turned on or varied, the electric field distribution is similar to that of AC voltage, but gradually the electric field becomes determined by the conductivities. Here, buildup of surface and space charge play an important role, resulting in a time dependent field distribution.

Typically the conductivity in most insulating materials strongly increases with increasing temperature while the permittivity is nearly constant. As illustrated in Fig.2 the electric field distribution within, DC cable insulation will become strongly dependent upon the current load, i.e. the temperature gradient across the insulation. As the temperature varies the ratio $\varepsilon / \sigma$ varies as well and a space charge $\rho$ is building up within the insulation. During current loading the initial capacitive AC field distribution will gradually change towards steady state DC distribution, where the increased insulation conductivity results in lower field stress in the inner warmest parts of the insulation.

It then follows that the resistively calculated DC field is equal to the sum of contributions from the capacitive field and that of surface or space charges: 


$$
\mathrm{E}_{\mathrm{DC}}=\mathrm{E}_{\mathrm{AC}}+\mathrm{E}_{\text {Charge }}
$$

After switching off a DC voltage, the remaining local space charges will only slowly vanish, often with a time constant,

$\tau=\varepsilon_{0} \varepsilon / \sigma$, equal to that when switching the voltage on. In many highly insulating materials the conductivity is extremely low and unknown. This is particularly so in case of interfaces between different materials. For instance in gas insulated systems using air or $\mathrm{SF}_{6}$ in combination with polymers. Due to the field emission of electrons and ions in the gases, the conductivity cannot be expressed in a value of $\sigma$. Then accumulation of the surface charge needs to be measured in order to calculate the electric field using eq.1.

After applying a DC voltage on a compressed gas installation, a steady state electric field distribution is typically reached in 2 to 5 hours [7]. The decay of the surface discharge after switching off the voltage, however, takes much longer time. A difference caused by the low conductivity at the low electric fields generated only by the charge itself.

If the voltage polarity of a warm cable is rapidly reversed, the AC field generated is superposed on the space charge induced field, resulting in a field enhancement close to the conductor. This is why type tests on HVDC cables always specify polarity reversals on fully loaded cables [8].

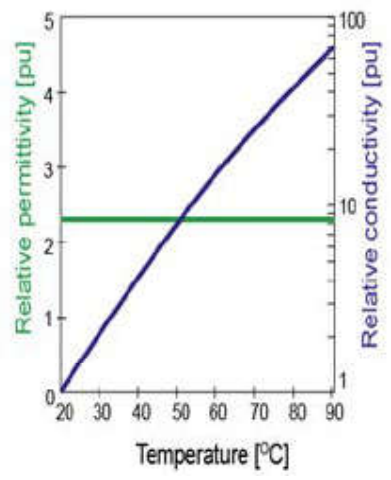

a)

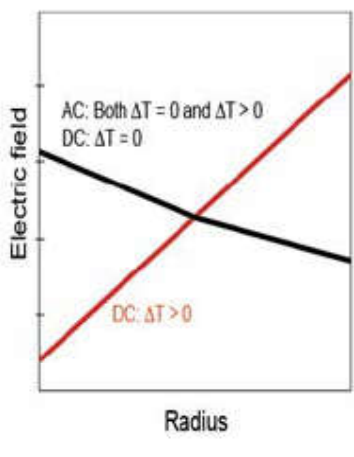

b)
Fig.2: a) Temperature dependence of the relative permittivity and conductivity. b) The resulting radial electrical field in a HVDC cable, changing from the initial black AC curve to the red curve in case of DC voltage and current load

In addition the conductivity is usually found to increase nonlinearly with the local electric field and it is difficult to predict how the value will vary with morphology and content of different additives [9]. Thus space charge and conductivity measurements are essential in order to characterize and verify the ability of an insulation system to withstand the stresses during HVDC voltages at different service conditions.

\section{ii) Limitation due to Irregularities}

Irregularities are usually limiting the electric design stress of any practical high voltage insulation system. They may appear as particle contaminants or cavities and are hard to avoid completely. To improve the longevity of for example extruded AC cables considerable effort has been made to avoid conductive particles and cavities. Insulating particles are less serious in AC cables as long as they are well bonded to the surrounding insulation. In DC insulation even insulating particles may cause local field enhancement as they are likely to have a different conductivity/ permittivity ratio than that of the surrounding insulation.

Several experiments using metallic needle plane arrangements in extruded polyethylene insulation $[10,11]$ have by applying a DC ramp voltage, found that electric tree inception occurs at a voltage that increased with decreasing rate of voltage rise. The calculated field strength at the needle tip exceeded by far expected values of the intrinsic breakdown strength of LDPE. This is explained to be caused by homo-charge injection into the region surrounding the needle tip. When given enough time to develop, this charge reduces the maximum field strength sufficiently to prevent treeing. This was further supported by experiments where the voltage polarity was reversed by applying an impulse voltage of opposite polarity to the applied DC field. It was then found that tree growth started at a much lower voltage. The effect of the voltage reversal was more marked the faster the reversal took place. It was even demonstrated that simply shortcircuiting the test specimen after DC poling was sufficient to cause treeing at a voltage lower than the DC tree inception voltage. The reason for this is supposed to be that the injected charge needs time to be removed when the test specimen is short-circuited, and that the field originating from the injected charge alone is sufficient to cause treeing. In addition to needle experiments are also made with conductive particles imbedded in the insulation, to better simulate particles likely to appear in a practical insulation. The time to breakdown in long term ageing experiments at average field strength of $100 \mathrm{kV} / \mathrm{mm}$ was not influenced by the particles, even though their size amounted to $15-20 \%$ of the insulation thickness [12].

Thus it is qualitatively well documented that conductive inclusions are particularly harmful in case of polarity reversals and rapid voltage transient. Such transients may occur during faults, even in installations with VSC technology. It is therefore of great importance that material handling and the manufacturing process is kept extremely clean, and that routine test procedures are available that can detect dangerous inclusion and defects in cable insulation.

\section{iii) Qualification and diagnostic tests}

In general electric breakdown is a weakest link mechanism, which means that one critical insulation irregularity may be sufficient to cause a service breakdown of the entire cable.

In order to avoid costly time outs and repairs of long distance HVDC cables it is essential to be able to reveal such weaknesses before cable installation. The test methods should therefore be applicable for voltage levels up to $500 \mathrm{kV}$, and for cable test length up to $50 \mathrm{~km}$ or more [13]. 
Routine testing of long HVAC cables is presently done using HVAC voltage. Generally the techniques used to generate the high $\mathrm{AC}$ test voltage limits the length of cable that can be tested. The maximum cable length, $\mathrm{L}_{\max }$, which can be energized by AC voltage, is according to the following relations limited by the frequency $f$, effective voltage $V$ and reactive power $Q$ supplied by the test equipment:

$$
\mathrm{L}_{\max } \propto \mathrm{C}_{\max }=\frac{\mathrm{Q}}{2 \pi \mathrm{fV}^{2}}
$$

where $C_{\max }$ is the total capacitance of the cable. In case of $\mathrm{AC}$ testing of long cable lengths, the test equipment needed becomes large and expensive, and finally the testing costs will limit the application of HVAC as routine test method for long HVDC cables. Thus, less power and probably more convenient low frequency test equipment can be used for testing of long cable lengths. However, before making such recommendations one needs to address the questions:

What frequency and voltage level should be used to detect typical critical flaws in an extruded HVDC cable system?

In addition methods for diagnosis and condition assessment of solids and oil-filled HVDC insulation systems are required in order to guarantee performance and reliability of HVDC transmission. Various, well established methods for the determination partial discharge levels and dielectric properties of the insulation materials can also be used in case of HVDC insulation. However, diagnosis and condition assessment of HVDC insulations requires measuring and evaluation of quantities that are especially related to the behavior of insulations under DC stresses. The electrical conductivity is such an important quantity, which usually has a strongly nonlinear dependence on various parameters (field strength, temperature, water content and aging products) and is time-dependent because of charge carrier drift processes.

Therefore, the conduction behavior contains a lot of possible diagnostic information, but special measuring methods are required to provide the necessary data.

HVDC mass impregnated cables have a long operational experience, as they have been in use as submarine cables for more than 50 years. During the latest decades extruded polymeric insulation has been the dominant choice of insulation for HVAC cable technology. Today the cable manufacturers therefore have a strong incentive to develop and produce HVDC cables with extruded polymeric insulation; cables that offers the same benefits; flexibility, lower weight and costeffectiveness, as the AC transmission cables. Today service experience with DC XLPE cables is limited to 10 years and voltage levels up to $+/-200 \mathrm{kV}$. New designs of reliable factory joints and modified CIGRE recommendations is expected to provide a base for the evaluation of the reliability of XLPE cable systems up to $+/-500 \mathrm{kV}$.

\section{CONCLUSIONS}

Global environmental issues and increasing need of renewable electric energy sources require electrical engineers to consider increased use of the more efficient DC power systems than the conventional AC transmission and distribution grids. In order to implement such a hybrid AC/DC grid, several challenges need to be addressed:

-New standards for DC voltage levels

-Design of HVDC power apparatus based upon reliable insulation systems and principles of current control and interruption.

-New qualification tests and condition assessment methodology adapted to critical breakdown and ageing mechanisms at HVDC stresses.

\section{REFERENCES}

[1] Edison Tech Center,"The History of Electrification: The birth of our power grid". http://edisontechcenter.org/

[2] Gunnar Asplund, "HVDC towards more power and higher voltage- a challenge for the insulation". Nord-Is 99 June 15-17, 2009 Gothenburg, Sweden.

[3] J.C. Fothergill, "Electric Insulation Systems for a Sustainable Energy Society", Nord-Is 99 June 15-17, 2009 Gothenburg, Sweden.

[4] E.Kolby and M.Hyttinen, "Challenges on the Road to an Off shore HVDC Grid", Nordic Wind Power Conf., Bornholm, Sept. 2009, Denmark.

[5] C.M.Frank, "HVDC Circuit Breakers: A Review Identifying Future Research Needs", IEEE Trans. On Power del. Vol.,26, No.2 April 2011.

[6] "ABB Solves 100 year old Electric Puzzle - New Technology to enable future DC grid”, Nov. 2012, http://www.abb.com

[7] F.H. Kreuger, Industrial High DC Voltage"Delft University Press, 1995

[8] E. Ildstad, et al., "Factors affecting the choice of Insulation system for extruded HVDC Power Cables," in CIGRE Symposium 2004, Paper D1-203.

[9] M. Goshowaki, et al., "Influence of antioxidants on electrical conduction in LDPE and XLPE," Journal of Electrostatics, vol. 65, pp. 551-554, Aug 2007.

[10] Ieda and Nawata, " DC Treeing breakdown associated with Space Charge formation", Vol . EI-12, No.1 1977.

[11] Ildstad, Selsjord, Mauseth et al: "Breakdown caused by abrupt DC-voltage grounding of XLPE cable insulation", Jicable'07, Paris, 2007.

[12] F.Mauseth, et al. "Quality Control of Extruded HVDC Cables: Detection of Critical Flaws using Low Frequency Voltage Endurance Testing”. ICHVE Conf. 2010 IEEE.

[13] WG 21.01: "Recommendations for Test of Power Transmission DC cables for rated voltage up to $600 \mathrm{kV}$ ", Cigré, 1980 